https://doi.org/10.1590/198053146645

\title{
VERTENTES EPISTEMOLÓGICAS DAS POLÍTICAS PÚBLICAS: ENTRE AS ANÁLISES DESCRITIVA E PRESCRITIVA
}

Bárbara Lucchesi Ramacciotti

Marjorie Cristina da Cruz Bernardino"

\section{Resumo}

Este artigo é uma pesquisa que visa a demonstrar a relevância do debate epistemológico para compreender as bases teóricas, vertentes e tipos de metodologia de análise que balizam o campo das políticas públicas, com base em revisão de literatura de autores clássicos como Putnam, Arretche, Farah, Secchi e Howlett. 0 estudo demonstra que a distinção entre fato e valor é importante para compreender a diferença entre a análise teórico-descritiva e a análise aplicada-prescritiva de políticas públicas, assim como a polêmica entre as vertentes positivistas e pós-positivistas que marcou a virada argumentativa a partir de 1990. Conclui-se que a compreensão das questões epistemológicas é de grande relevância para fundamentar metodologias de análise.

\section{EPISTEMOLOGIA • POLÍTICAS PÚBLICAS • POSITIVISMO}

\section{EPISTEMOLOGICAL STRANDS OF PUBLIC POLICIES: BETWEEN DESCRIPTIVE AND PRESCRIPTIVE ANALYSES}

\section{Abstract}

This article aims to demonstrate the relevance of the epistemological debate to understand the theoretical bases, the strands and the types of analysis methodology that target the field of public policies. This is a theoretical-explanatory research, based on a literature review of classical authors, such as Putnam, Arretche, Farah, Secchi and Howlett. The study demonstrates that the epistemological distinction between fact and value is an important key to understand on the one hand, the difference between the theoretical-descriptive analysis and the applied-prescriptive analysis of public policies, and on the other, the controversy between the positivist and post positivist strands, which marked the argumentative turn starting in 1990. It was concluded that the understanding of the epistemological issues is of great relevance to the rationale behind the analysis methodologies.

\section{EPISTEMOLOGY • PUBLIC POLICIES • POSITIVISM}


COURANTS ÉPISTÉMOLOGIQUES DES POLITIQUES PUBLIQUES: ENTRE LES ANALYSES DESCRIPTIVES ET PRESCRIPTIVES

\section{Résumé}

L'objectif de cet article est de demontrer l'importance du débat épistémologique pour comprendre quelles sont les bases théoriques, les différents courants et les types de méthodologie d'analyse qui servent de répère au domaine des politiques publiques. Après avoir passé en revue les travaux classiques sur le sujet des auteurs tels que Putnam, Arretche, Farah, Secchi et Howlett, ce travail démontre que la distinction entre fait et valeur est importante pour comprendre non seulement la différence entre l'analyse théorique descriptive et l'analyse appliquée prescriptive des politiques publiques, mais aussi la controverse entre les courants positivistes et post-positivistes à l'origine du tournant argumentatif initié en 1990. La conclusion montre que la compréhension des questions épistémologiques est d'une grande pertinence pour étayer les méthodologies d'analyse.

\section{ÉPISTEMOLOGIE • POLITIQUES PUBLIQUES・POSITIVISME}

\section{VERTIENTES EPISTEMOLÓGICAS DE LAS POLITICAS PÚBLICAS: ENTRE LOS ANÁLISIS DESCRIPTIVO Y PRESCRIPTIVO}

\section{Resumen}

Este artículo es una investigación que tiene como objetivo demostrar la relevancia del debate epistemológico para comprender las bases teóricas, las vertientes y tipos de metodología de análisis que guían el campo de las Políticas Públicas, basándose para ello en la revisión de la literatura de autores clásicos, como Putnam, Arretche, Farah, Secchi y Howlett. Se demuestra que la distinción entre hecho y valor es importante para comprender la diferencia entre el análisis teórico-descriptivo y el análisis aplicado-prescriptivo de políticas públicas. Del mismo modo es significativa la controversia entre las vertientes positivistas y pospositivistas que marcó un punto de inflexión a partir de 1990. Se concluye que la comprensión de las cuestiones epistemológicas es de gran relevancia para fundamentar las metodologías de análisis. 
STE ARTIGO VISA A UMA BREVE REVISÃO DO DEBATE EPISTEMOLÓGICO EM TORNO DA distinção entre fato e valor para compreender: i) as diferenças entre a análise de política pública, ou análise teórico-descritiva (policy studies), e a análise para política pública, ou análise prescritiva (policy analysis); e ii) a polêmica entre a vertentes positivistas ou racionalista e pós-positivistas ou argumentativa/construtivista, as quais balizam o campo da Política Pública. Partimos da hipótese segundo a qual o exame do debate epistemológico é uma chave importante para compreender a distinção teórica e metodológica entre as principais vertentes de pesquisa em Política Pública.

Para verificar a hipótese e atingir o objetivo proposto dividimos o estudo em três partes. A primeira traz uma breve revisão do debate epistemológico em torno da distinção entre fato e valor, tendo por referência a obra seminal de Hilary Putnam, O colapso da verdade (2008). A segunda examina a distinção entre as atividades de policy analysis e de policy studies, tendo por referência a revisão de Secchi (2016), e o debate em torno das atividades de análise e avaliação de ou para as políticas públicas, tendo por base os artigos de Arretche (1998) e Farah (2016). A terceira verifica a polarização do campo teórico da Política Pública entre as vertentes positivistas ou racionalistas e pós-positivistas ou argumentativas, polêmica que marcou a chamada "virada argumentativa” a partir da década de 1990, tendo por referência Secchi (2016) e Howlett, Ramesh e Perl (2013). 


\section{DISTINÇÃO EPISTEMOLÓGICA ENTRE FATO E VALOR}

Boa parte do debate filosófico clássico e epistemológico contemporâneo gira em torno da distinção entre o domínio do ser, das coisas ou dos fenômenos que podem ser observados e examinados à luz da razão natural (sentidos, intelecto e linguagem), e o domínio do dever ser, ou seja, do campo da ação humana (ética, política, economia), que depende do interesse, da vontade, da finalidade.

No contexto da revolução filosófico-científica que marca o início da modernidade, sobretudo com a filosofia de Descartes no século XVII, a distinção entre o ser, ou a realidade determinada por causas naturais e necessárias, e a realidade do pensar e do dever ser, ou seja, o reino determinado por causas finais ou o mundo humano do pensamento, da ação moral e da liberdade de escolha, é traduzida pelo dualismo entre res extensa e res cogitans. O dualismo substancial cartesiano além de estabelecer as substâncias extensa (sensível) e pensante (inteligível) como princípios constitutivos de todo real, fixa a relação entre sujeito (mente) e objeto (corpos) como base de todo conhecimento: "De sorte que esse eu, isto é, a alma (mente) pela qual sou o que sou, é inteiramente distinta do corpo e, mesmo, que é mais fácil de conhecer do que ele, e, ainda que este nada fosse, ela não deixaria de ser tudo o que é” (DESCARTES, 1973, p. 55). Essa relação dualista entre mente e corpo é a via para a dedução do célebre argumento do "cogito, ergo sum”. A primeira regra do método dedutivo (racionalismo moderno) adota a certeza ou autoevidência do argumento do cogito como critério para verificação da verdade: uma ideia, para ser verdadeira, precisa ser clara, distinta e indubitável.

E, tendo notado que nada há no eu penso, logo existo, que me assegure de que digo a verdade, exceto que vejo muito claramente que, para pensar, é preciso existir, julguei poder tomar por regra geral que as coisas que concebemos mui clara e mui distintamente são todas verdadeiras, havendo apenas alguma dificuldade em notar bem quais são as que concebemos distintamente. (DESCARTES, 1973, p. 55)

Interessa-nos aqui examinar apenas a distinção entre o domínio do ser e do dever ser. Apesar das várias mutações sofridas por tal distinção ao longo da história da filosofia, Hume, representante do empirismo moderno, foi o primeiro filósofo a colocar o problema em termos da diferença entre "questões de fato" e “questões morais”, no Tratado da natureza humana: "a moralidade não consiste em relações que são objeto da ciência [...] não consiste em nenhuma questão de fato que possa ser descoberta pelo entendimento” (HUME, 2009, livro 3, parte 1, seção 1, p. 508). Em outra passagem, Hume afirma: "Em todo sistema moral [...] surpreendo-me ao ver que, em vez das cópulas proposicionais usuais, como é ou não é, não encontro uma só proposição que não esteja conectada uma a outra por um deve ou não-deve" (2009, livro 3, parte 1, seção 1, p. 509).

Segundo Mariconda (2006), essa célebre passagem tem sido interpretada como o "princípio de Hume", difundido pela seguinte fórmula: não se podem extrair dos conhecimentos científicos sobre os fatos conclusões no domínio dos 
valores; ou, ainda, fatos não implicam valores. Hume estabelece a distinção entre as "questões de fato" e os objetos da filosofia moral, tais como paixões, afetos, emoções e sentimentos. Esse conjunto de objetos que se generaliza na expressão "questão de valor".

Putnam, em 0 colapso da verdade (2008), já havia destacado que a distinção humana entre fato e valor, ou entre conhecimento científico descritivo dos fatos e avaliação moral, foi exacerbada na década de 1930 pelos positivistas lógicos, que a transformaram em uma "dicotomia”. Putnam observa que uma distinção filosófica é bem diferente de uma dicotomia, ou seja, de um "dualismo filosófico pernicioso" (2008, p. 22), pois este estabelece uma hierarquia entre os termos, desvalorizando ou desqualificando um deles. No caso, os positivistas lógicos partem da dicotomia entre fato e valor para desqualificar todos os enunciados metafísicos e "os enunciados éticos (bem e mal) e estéticos (belo e feio)" como sem "significado cognitivo", pois "não expressam propriamente conhecimento" (MARICONDA, 2006, p. 454). A redução operada pelos positivistas lógicos da distinção filosófica entre fato e valor à condição de dicotomia pressupõe que "juízos de valor são subjetivos”, ou seja, não possuem significado cognitivo em termos de conhecimento objetivo.

Para entender como os positivistas lógicos transformam a distinção de Hume entre fato e valor em uma dicotomia radical, para desqualificar os juízos de valor, sobretudo os juízos éticos, estéticos e metafísicos, como "sem sentido”, é preciso entender o reducionismo que operaram na distinção kantiana entre juízos analítico e sintético. ${ }^{1}$ Essa é a tese defendida pelo epistemólogo estadunidense Hilary Putnam (2008).

Putnam observa que essa redução foi introduzida pela "famosa classificação tripartite de todos os nossos juízos” apresentada pelos positivistas lógicos (2008, p. 23): i) os juízos “sintéticos” (empiricamente verificáveis ou falsificáveis); ii) os "analíticos" (verdadeiros ou falsos, somente com base nas regras lógicas); iii) os cognitivamente carentes de significado (o que inclui todos os juízos éticos, estéticos e metafísicos), embora possam ter uma função prática enquanto imperativos. Putnam destaca que

\footnotetext{
Essa exclusão dos enunciados éticos do domínio do discurso racional recebeu uma expressão veemente por parte de Carnap (1932, p. 26-7)² em The unity of Science. Após explicar que todos os problemas não-científicos são uma confusão [...] de pseudoproblemas, ele escreve:

Todos os enunciados pertencentes à metafísica, à ética regulativa [...] possuem esse defeito; são de fato, inverificáveis
}

Na "Introdução" à Crítica da razão pura, Kant (2001) define juízo como um ato que relaciona um predicado e um sujeito (S é P). E apresenta a distinção entre juízos no tópico VI: "A diferença entre juízo analítico e sintético". No juízo analítico ou explicativo, o predicado está contido na definição do sujeito; por exemplo, "todos os corpos são extensos". A extensão constitui a essência dos corpos, permite explicar o que é o sujeito, mas não acrescenta nada além do predicado/atributo essencial. Os juízos analíticos são puros ou a priori, pois não dependem da experiência a posteriori para comprovação. No juízo sintético, o predicado é completamente estranho ao sujeito. Podendo ser de dois tipos: a priori ou a posteriori. "Os juízos sintéticos a posteriori, a prova da ligação entre o predicado e o sujeito deve vir de fora, da experiência. Ex.: 'todos os corpos são pesados'”. A gravidade não pertence à essência dos corpos, só pode ser apreendida em uma intuição empírica. No juízo sintético a priori, a ligação entre predicado e sujeito apresenta um caráter necessário e eterno. Ela se apoia em uma experiência de pensamento em uma intuição pura. 
e, portanto, não-científicos. No Círculo de Viena, estamos acostumados a descrever tais enunciados como sem sentido (seguindo Wittgenstein). Deve-se entender que essa terminologia implica uma distinção lógica e não-psicológica; pretende-se que seu uso assevere apenas que os enunciados em questão não possuem uma certa característica lógica comum a todos os enunciados propriamente científicos [a saber, verificabilidade] [...] (PUTNAM, 2008, p. 33)

Para estabelecer essa redução dos juízos analíticos a critérios lógicos, dos empíricos à significação de fato e dos juízos de valor a proposições sem sentido, Carnap descontextualiza a tese do Tratado lógico-filosófico (TLP) de Wittgenstein (1987), segundo a qual as proposições analisadas logicamente, cujo nome conote algum objeto (3.203), possuem sentido, sendo o sentido expresso por um fato (TLP, 3.14 e 3.142). Com base nesse critério de referência a um fato, Wittgenstein afirma que as proposições metafísicas são pseudoproposições, ou seja, são desprovidas de sentido (4.003), pois os nomes ou termos dessas proposições não conotam nada na realidade, falam de um sentido que está fora do mundo (641), por isso não se referem a nada de real, do que se conclui que sejam sem sentido. ${ }^{3}$

Com base nessa tese, Carnap opera três reducionismos: (i) transforma a distinção entre fato e valor de Hume em uma dicotomia; (ii) exacerba a distinção kantiana entre juízos analíticos e sintéticos; (iii) aplica a distinção de Wittgenstein entre as proposições lógicas (que conotam um sentido, um fato) e as proposições metafísicas (sem sentido conotativo) à toda proposição ética e estética, porque estas apenas denotam um juízo de valor.

Putnam observa que, no ensaio de 1953, "Two dogmas of empiricism" [Dois dogmas do empirismo], Quine já havia demolido a noção (exacerbada) de "analiticidade" de Carnap, pois recusa a tese segundo a qual a linguagem científica está dividida entre uma parte "fatual” e outra analítica. Quine, um dos expoentes da filosofia analítica nos Estados Unidos, apesar de adotar o ponto de vista do empirismo lógico, afirma nesse texto que o primeiro dogma que Carnap precisa abandonar para tornar o empirismo imune a qualquer crítica é a crença na separação entre linguagem e fatos, entre verdades analíticas e verdades sintéticas. Para Quine, as verdades analíticas (a priori) não existem, pois toda verdade depende ao mesmo tempo da linguagem e dos fatos.

O empirismo moderno foi em grande parte condicionado por dois dogmas. Um deles é a crença em certa divisão fundamental entre verdades analíticas, ou fundadas em significados independentes de questões de fato, e verdades sintéticas, ou fundadas em fatos. O outro dogma é o reducionismo: a crença de que todo enunciado significativo é equivalente a algum 
Segundo Putnam, a dicotomia fato/valor foi inflada pelo positivismo lógico como via para excluir as proposições éticas e as questões de valor do âmbito do debate epistemológico. Contudo, diferente de Quine, Putnam não recusa a distinção entre verdades analíticas e verdades sintéticas de tipo observacional (2008, p. 23). Para esse autor, é importante manter a distinção entre fato e valor e, ao mesmo tempo, compreender a relevância da imbricação entre fatos e valores para a metodologia das ciências, pois toda atividade científica, além de envolver valores éticos e sociais, está fundada em valores cognitivos.

Para compreender a imbricação entre fato e valor, ou a inseparabilidade entre conhecimento descritivo e normativo ou prescritivo, é preciso reconhecer a existência de valores cognitivos como critérios de verificação da objetividade do conhecimento científico, ultrapassando o reducionismo da dicotomia fato/valor posta pelos positivistas lógicos. No capítulo 2 de 0 colapso da verdade (2008), Putnam explora a dupla tese da imbricação entre fato e valor e da distinção entre tipos de valores como estratégia para ampliar o debate no campo da epistemologia das ciências. Destacamos alguns argumentos de Putnam:

(I) É importante diferenciar os valores epistêmicos de outros tipos de valores, incluindo os éticos, para desfazer a crença positivista de que a ciência é livre de valores: "Dizer que valores epistêmicos são valores, como acabo de fazer, não é, por certo, negar que existem diferenças entre valores epistêmicos e valores éticos" (2008, p. 51).

(II) As questões de fato e as questões de valor estão imbricadas, pois descrição de fatos e prescrição ou avaliação com base em valores (sociais, éticos, econômicos, políticos) são procedimentos interdependentes, sobretudo se quisermos fazer uma análise responsável das implicações da ciência e dos usos da tecnologia na atualidade.

(III) A distinção entre valores normativos e valores epistêmicos e a imbricação entre juízos descritivo (fato) e normativo (valor) não são teses originais, pois já eram adotadas pelos filósofos do pragmatismo americano:

Todos os pragmatistas: Pierce, James, Dewey e Mead sustentam que valor e normatividade permeiam toda experiência. Na filosofia da ciência, esse ponto de vista significa que juízos normativos são essenciais para a prática científica. Os pragmatistas não se referiam apenas a juízos normativos que chamamos de "morais" ou "éticos", mas juízos acerca da "coerência”, "plausibilidade”, "razoabilidade”, "simplicidade”. (PUTNAM, 2008, p. 50) 
Ao analisar a relação fato e valor a partir da leitura de Putnam, visamos a colocar em pauta a tese defendida pelo autor: confrontar "a visão daqueles que defendem que 'enunciados de fato' são 'objetivamente verdadeiros', enquanto 'juízos de valor' são incapazes de verdade objetiva e de garantia objetiva” (2008, p. 13). Nesse sentido, Putnam defende que a distinção fato/valor, que fundamenta boa parte da reflexão epistemológica sobre a verdade, é uma criação filosófica equivocada e reducionista: “A ideia de que 'juízos de valor são subjetivos’ é uma criação da filosofia que veio a ser gradualmente aceita por muitas pessoas, como se fizesse parte do senso comum" (2008, p. 13).

O redirecionamento da análise da relação entre linguagem e ética proposto por Putnam a partir dessas duas teses implica não só a abertura do debate da epistemologia para as questões éticas, mas implica também a validação de outras metodologias e estratégias de pesquisa que não se limitem aos critérios lógico (matemático, estatístico, quantitativo) e empírico. Em outras palavras, tal abertura possibilita a escolha de análises normativas e prescritivas com base em valores éticos, sociais e políticos como procedimento para as pesquisas científicas, não só no campo das ciências humanas e sociais aplicadas, mas no campo das ciências em geral.

Como exemplo dessa abertura epistemológica para o campo da ética, Putnam examina, no capítulo 3, intitulado, "Fato e valor no mundo de Amartya Sen", o caso do Prêmio Nobel de economia do ano de 1974, que defendeu outro paradigma de racionalidade econômica, tendo por fundamento "questões do bem-estar social" mensuradas e avaliadas com base em critérios e indicadores éticos e sociais. Nas palavras de Amartya Sen: "Tentei argumentar que a economia de bem-estar pode ser substancialmente enriquecida prestando mais atenção à ética e que o estudo da ética pode também beneficiar-se de um contato mais próximo com a economia" (19875, p. 89, apud PUTNAM, 2008, p. 91).

As pesquisas de Amartya Sen sobre a economia do bem-estar com base em valores éticos inauguraram um novo paradigma de racionalidade para a ação dos sujeitos individuais e coletivos, tais como os atores políticos e o Estado, em contraponto ao paradigma da racionalidade econômica com base na maximização da utilidade (da eficácia e da eficiência) adotado como modelo nas principais teorias de tomada de decisão, incluindo o campo da Política Pública. Esse novo paradigma amplia o debate no contexto do Estado de bem-estar social e das políticas públicas, pois traz o conceito de desenvolvimento social e humano e de indicadores sociais, retirando o primado do conceito de desenvolvimento e dos indicadores analíticos puramente econômicos.

\section{ANÁLISE DESCRITIVA E PRESCRITIVA DE POLÍTICA PÚBLICA}

No campo da ciência da Política Pública, parece que a posição positivista a respeito da dicotomia radical entre fato e valor não teve grande relevância, já que essa área de pesquisa desde sua fundação estabelece duas atividades como constitutivas: o estudo (teórico, descritivo, explicativo) de política pública (policy studies) e a 
análise (prática, aplicada, prescritiva) para política pública (policy analysis), sobretudo com base em valores da racionalidade econômica. Entretanto, essa conclusão é um pouco apressada, vejamos o porquê. O fato de a ciência da Política Pública em sua fundação estabelecer a distinção entre estudo teórico descritivo (fato) e análise aplicada e prescritiva (valor) não significa que não existam polêmicas quanto às bases epistemológicas e metodológicas. É o que se pretende examinar neste tópico.

O livro de David Lerner e Harold Lasswell, The policy sciences (1951), é considerado o marco fundador da ciência da política pública (policy sciences). O capítulo escrito por Lasswell, “The policy orientation”, enfatiza a atividade aplicada e prática da análise de política pública (policy analysis) para a solução de problemas públicos como elemento central dessa nova área de conhecimento, conforme consenso de diversos autores (DUNN, 19816; DURNING, 19937; HOWLETT, RAMESH, PERL, 2013; FISCHER, 2003, p. 15², apud SECCHI, 2016, p. 12).

Nesse mesmo capítulo, Lasswell (1951) estabelece a distinção entre o estudo de políticas públicas (policy studies) e a análise de políticas (policy analysis) como duas vertentes das policy sciences: "uma orientada à busca de conhecimento sobre o processo de política pública (policy studies) e outra orientada para as políticas (policy analysis)" (FARAH, 2016, p. 962).

Secchi (2016) observa que a distinção entre a pesquisa ou o estudo (teórico) de política pública (policy research ou policy studies) e a análise de política pública (policy analysis) é recorrente na literatura internacional. Coloca em relevo as diferenças metodológicas desses dois tipos de atividades quanto a finalidade e quanto aos meios ou métodos empregados. Quanto à finalidade, os estudos são divididos em descritivos (explicativos, teóricos) e prescritivos (aplicados, práticos).

\begin{abstract}
Do ponto de vista da finalidade, os estudos podem ser divididos em descritivos e prescritivos. Estudo de cunho descritivo tem por objetivo construir teorias, por meio da descrição e explicação dos tipos de políticas públicas, do comportamento dos atores e das instituições, nas diversas fases do processo de política pública. Já os estudos de cunho prescritivo estão em "melhorar" as políticas públicas, ou seja, apontar como elas deveriam ser. Prescrição significa recomendação, orientação, intervenção [...], para isso, baseiam-se em valores de equidade, eficiência, eficácia, resiliência, entre outros. (SECCHI, 2016, p. 8)
\end{abstract}

Na revisão de Secchi (2016), fica demonstrado que o sentido prescritivo do termo policy analysis está consolidado na literatura internacional. Diversos autores de variadas vertentes concordam com essa finalidade prática: a análise de política 
pública voltada à recomendação de solução para um problema público. Conforme quadro abaixo:

QUADRO 1

DEFINIÇÕES DE ANÁLISE DE POLÍTICAS PÚBLICAS

\begin{tabular}{|c|c|}
\hline AUTOR & DEFINIÇÃO \\
\hline $\begin{array}{l}\text { DUNN } \\
(1981, p . i x)\end{array}$ & $\begin{array}{l}\text { "Análise de política pública é uma disciplina de ciência social aplicada que usa } \\
\text { múltiplas metodologias de pesquisa e argumentação para produzir e transformar } \\
\text { informações relevantes que poderão ser utilizadas no contexto político para } \\
\text { resolver problemas públicos". }\end{array}$ \\
\hline $\begin{array}{l}\text { TORGERSON } \\
(1986, \text { p. } 33)^{9}\end{array}$ & $\begin{array}{l}\text { "[...] atividades voltadas para o desenvolvimento de conhecimento relevante para } \\
\text { a formulação e implementação de política pública." }\end{array}$ \\
\hline $\begin{array}{l}\text { PATTON, SAWICKI } \\
(1993, \text { p. } 24)^{10}\end{array}$ & $\begin{array}{l}\text { "Análise de política pública é [...] uma avaliação sistemática da viabilidade } \\
\text { técnica, econômica e política de alternativas de policy (ou planos ou programas) } \\
\text { estratégias de implementação, e as consequências da sua adoção." }\end{array}$ \\
\hline $\begin{array}{l}\text { BOBROW, DRIZEK } \\
(1987, \text { p. } 16)^{11}\end{array}$ & $\begin{array}{l}\text { "[...] a essência da análise de política pública reside na intervenção com base em } \\
\text { conhecimento para o processo de construção de política pública." }\end{array}$ \\
\hline $\begin{array}{l}\text { YANOW } \\
(2000, \text { p. viii) })^{12}\end{array}$ & $\begin{array}{l}\text { "Análise de política pública busca informar algum público - tradicionalmente o } \\
\text { tomador de decisão - sobre um potencial política pública: qual será seu impacto } \\
\text { sobre a população alvo, se tem chances de atingir os objetivos desejados, se é } \\
\text { política correta para enfrentar um problema específico." }\end{array}$ \\
\hline $\begin{array}{l}\text { WEIMER, VINNING } \\
(2011, \text { p. } 24)^{13}\end{array}$ & $\begin{array}{l}\text { "Análise de política pública é uma recomendação relevante para a decisão pública, } \\
\text { orientada a um cliente e informada por valores sociais." }\end{array}$ \\
\hline
\end{tabular}

Fonte: Elaboração dos autores com base em Secchi (2016, p. 11).

Secchi sublinha que as definições acima "tratam a análise como campo teórico e metodológico (disciplina), como uma atividade (avaliação sistemática) ou até como produto (recomendação)” (2016, p. 11). E concordam quanto à finalidade prescritiva: elaborar políticas públicas, avaliar questões técnico-políticas e gerar informação para tomadas de decisões e enfrentamento de problemas públicos.

Apesar da distinção entre as atividades de policy research e policy analysis na literatura internacional, Secchi (2016) destaca que no Brasil o termo policy analysis, traduzido por análise de política pública, "carece de homogeneidade e entendimento", sendo usado em sentido amplo e em geral "limitado à atividade de pesquisa acadêmica, descritiva, voltada à construção teórica relacionada a fenômenos de política pública" (FARIA, 2003 ${ }^{14}$, apud SECCHI, 2016, p. 11; GARCIA; XAVIER, 2012 ${ }^{15}$, apud SECCHI, 2016, p. 11; CAVALCANTI, 2012 ${ }^{16}$, apud SECCHI, 2016, p. 11). Para evitar a dificuldade terminológica, alguns autores usam "análise de política pública” para se referir à tarefa descritiva de construção teórica e “análise para política pública” para se referir à tarefa prescritiva de intervenção Prentice-Hall, 1993.

11 BOBROW, Davis B.; DRYZEK, John S. Policy analysis by design. Pittsburgh, PA: University of Pittsburgh Press, 1987.

12 YANOW, Dvora. Conducting interpretive policy analysis. Thousand Oaks, CA: Sage, 2000.

13 WEIMER, David L.; VINING, Aidan R. Policy analysis: concept and practice. 5. ed. Upper Saddle River, NJ: Prentice Hall, 2011. FARIA, C. A. P de. Ideias, conhecimento e políticas públicas: um inventário sucinto das principais vertentes analíticas recentes. Revista Brasileira de Ciências Sociais, v. 18, n. 51, p. 21-29, fev. 2003.

15 GARCIA, Maria L. T.; XAVIER, F. Análise de políticas públicas: temas, agenda, processos e produtos. São Paulo: Annablume, 2012

16 CAVALCANTI, Paula Arcoverde. Análise de políticas públicas: o estudo do Estado em ação. Salvador: Eduneb, 2012. 
prática (VAITSMAN; RIBEIRO; ANDRADE, 2013 ${ }^{17}$; FARAH, 2013 ${ }^{18}$; DRAIBE, $2014^{19}$ apud SECCHI, 2016, p. 12).

Dentre os autores que fazem essa distinção entre análise de e análise para política pública, destacamos o artigo de Marta Farah (2016), que traz uma boa revisão sobre a trajetória das políticas públicas no Brasil, desde 1930, como policy analysis, ou como análise para política pública aplicada e técnica, até a institucionalização da área como policy studies nas universidades como análise de política pública, a partir dos anos 2000:

Os estudos de políticas, segundo essa tradição, são desenvolvidos por acadêmicos e dizem respeito à natureza das atividades do Estado, procurando entender e explicar o processo da política pública assim como os modelos utilizados por pesquisadores para analisar o processo de formulação e implementação de políticas (DOBUZINSKIS, HOWLETT e LAYCOCK, $2007^{20}$ ). A análise de políticas, por sua vez, corresponde a estudos para políticas, envolvendo a geração e a mobilização de conhecimento para subsidiar políticas públicas (FARAH, 2013a ${ }^{21}$ ). Dobunzinskis, Howlett e Laycock (2007:3-4) destacam esse caráter aplicado, definindo a análise de políticas como a aplicação de pesquisa científica e de outras formas de conhecimento na formulação, implementação e avaliação de políticas. (FARAH, 2016, p. 962)

Outros autores empregam o termo análise para referir-se à pesquisa teórica, e o termo avaliação para designar o conhecimento aplicado e técnico. Destacamos a revisão de Arretche (1998) sobre a distinção entre as atividades de análise e de avaliação de política pública. A autora segue Figueiredo e Figueiredo (1986, p. $2^{22}$ ) na definição de avaliação de política pública como "a elucidação do critério ou critérios que fundamentam determinada política: as razões que a tornam preferível a qualquer outra” (apud ARRETCHE, 1998, p. 2). Nesse sentido, a avaliação política pode ressaltar quer o caráter político do processo decisório que implicou a adoção de uma dada política, quer os valores e critérios políticos nela identificáveis.

Já por análise de políticas públicas, Arretche entende "o exame da engenharia institucional e dos traços constitutivos dos programas. Qualquer política pública pode ser formulada e implementada de diversos modos” (1998, p. 2). Jeni; RIBEIRO, José Mendes; LOBATO, Lenaura. Policy analysis in Brazil. Bristol: Policy, 2013. Lenaura. Policy analysis in Brazil. Bristol: Policy, 2013

19 DRAIBE, Sonia. Policy analysis in Brazil: emergence and institutionalisation. Brazilian Political Sciences Review, v. 8, n. 2, p. 188-122, 2014

20 DOBUZINSKIS, Laurent; HOWLETT, Michael; LAYCOCK, David. Policy analysis in Canada: the state of art. Toronto: University of Toronto Press, 2007

21 FARAH, Marta F. S. Policy analysis at the municipal level of government. In: VAITSMAN, Jeni; RIBEIRO, José M.; LOBATO Lenaura. Policy analysis in Brazil. Bristol: Policy, 2013a. p. 107-118

22 FIGUEIREDO, Marcus Faria; FIGUEIREDO, Argelina Maria Cheibub. Avaliação política e avaliação de politicas: um quadro de referência teórica. Textos IDESP, n. 15, 1986. mimeo. 
Mesmo não usando a distinção clássica entre análise e estudo de política pública nem os adjetivos sugeridos por Secchi (descritivo e prescritivo), a autora caracteriza a avaliação pelo sentido aplicado, prescritivo e prático em distinção à análise:

\footnotetext{
Ainda que a análise de uma dada política pública possa atribuir a um determinado desenho institucional alguns resultados prováveis, somente a avaliação desta política poderá atribuir uma relação de causalidade entre um programa x e um resultado y. (1998, p. 2)
}

Arretche também afirma que na literatura específica a avaliação de políticas públicas é uma atividade de análise que envolve valores, tais como: efetividade, eficácia e eficiência. O exame da avaliação conforme os três tipos de valores (efetividade, eficácia e eficiência) é o objeto do artigo de Arretche.

Para uma unidade terminológica no campo das políticas públicas no Brasil sobre a distinção entre policy studies e policy analysis, talvez fosse uma alternativa o emprego da expressão análise descritiva, para se referir às análises teóricas de política pública de base descritiva, explicativa e argumentativa, e análise prescritiva, para se referir às avaliações aplicadas e técnicas, que visam a formular recomendações, ajustes e correções. A distinção entre análise e avaliação é amplamente empregada na literatura no Brasil. Os adjetivos descritivo e prescritivo marcam os métodos característicos das atividades de pesquisa teórica e análise aplicada de política pública, além de remeter à distinção epistemológica clássica entre fato (descrição) e valor (prescrição, avaliação).

\section{VERTENTE POSITIVISTA E PÓS-POSITIVISTA/ARGUMENTTIVA}

A ciência da Política Pública surge, com Lasswell (1951), como o campo da policy analysis, ou seja, da análise aplicada e prescritiva voltada à formulação de política pública tendo por referência, sobretudo, o paradigma da racionalidade econômica que estabelece os valores de eficácia, eficiência e efetividade como critérios centrais para a tomada de decisão inclusive na administração pública. Além de Lasswell, outros três fundadores do campo metodológico das políticas públicas também adotam o racionalismo econômico de base positivista como paradigma, a saber: o racionalismo limitado de Simon (1955/2014), o incrementalismo de Lindblom (1979/2014a, 2014b), o modelo de sistemas de Easton (1965). Todos esses modelos se inscrevem no campo da racionalidade econômica de matiz positivista, pois fundamentam as análises da eficiência e da eficácia econômica por meio de métodos que visam à maximização dos resultados por meio de critérios como custo-benefício, custo-efetividade, simplicidade, entre outros.

Nos anos 1970 surgem importantes livros, observa Secchi (2016), que reforçam as metodologias positivistas de caráter prescritivo e racionalista da análise de políticas públicas, com forte ênfase na eficiência econômica (DROR, 1971²3; 
HECLO, 1972 ${ }^{24}$; STOKEY; ZECKHAUSER, 1978²5; WIDAVSKY, 1979²6, apud SECCHI, 2016). E, nos anos 1980, surgem importantes manuais metodológicos para a análise racionalista-positivista de política pública (DUNN, 1981, apud SECCHI, 2016; WEIMER; VINING, 1989 apud SECCHI, 2016).

A diversificação metodológica do campo ocorreu, segundo Secchi, somente a partir dos anos 1980, com uma nova abordagem teórico-metodológica de análise de política pública: a abordagem argumentativa. "Inspirada em novas contribuições da filosofia e das ciências sociais, como o interpretativismo de Geertz $\left(1973^{27}\right)$, a teoria do agir comunicativo de Habermas $\left(1970^{28}\right)$ e a filosofia pragmática de Rorty (1982 ${ }^{29}$ )” (SECCHI, 2016, p. 14).

Nos anos 1990, ocorreu a chamada "virada argumentativa" (argumentative turn), que marcou o surgimento de um novo campo teórico e metodológico, "em que muitos teóricos passaram a reivindicar modelos analíticos em um perfil pós-positivista, discursivo, argumentativo, narrativo, crítico, interpretativo e de construtivismo social" (FISCHER; FORESTER, 1993, apud SECCHI, 2016, p. 14; SCHNEIDER; INGRAM, 199330, apud SECCHI, 2016, p. 14). Secchi ainda destaca que, "Nos anos 2000, a divisão do campo entre correntes positivistas (racionalistas) e pós-positivistas (argumentativas) provocou o nascimento de comunidades epistemológicas separadas” (2016, p. 14).

Portanto, verifica-se que esse debate epistemológico entre positivistas e pós-positivistas não é coisa do passado nem um debate restrito ao campo da filosofia da ciência (epistemologia). A dicotomia entre fato e valor, entre positivistas e pós-positivistas, encontra as mais diversas atualizações em diferentes campos da ciência, por ser uma discussão epistemológica de base.

Assim, o campo das Políticas Públicas também se encontra cindido entre, de um lado, a vertente positivista ou neopositivista, que adota o paradigma do racionalismo utilitarista, e os métodos quantitativos de base matemática, estatística e experimental como principais instrumentos de pesquisas; de outro, a vertente pós-positivista, que adota as abordagens argumentativas e prioriza os métodos qualitativos de base interpretativa e construtivista. A perspectiva metodológica argumentativa e qualitativa considera, além dos valores da racionalidade econômica (eficácia, eficiência, custo-benefício), os valores políticos, sociais e éticos como critérios e indicadores para fundamentar suas análises (viabilidade política, equidade social, justiça social, bem-estar, etc.). Recusa o monismo metodológico positivista que considera apenas os valores cognitivos de base lógica, matemática e experimental e os valores do racionalismo econômico como objetivos ou válidos.

Secchi observa ainda que:

\footnotetext{
HECLO, Hugh. Policy analysis. British Journal of Political Science, v. 2, n. 1, p. 83-108, jan. 1972.

STOKEY, Edith; ZECKHAUSER, Richard J. A primer for policy analysis. Nova York: W. W. Norton \& Company, 1978

WILDAVSKY, Aaron. Speaking truth to power: the art and craft of policy analysis. Boston: Little, Brown, 1979

GEERTZ, Clifford. The interpretation of cultures. Nova York: Basic Books, 1973

HABERMAS, Jurgen. Toward a rational society: student protest, science, and politics. Boston: Beacon, 1970

RORTY, Richard. Consequences of pragmatismo. Minneapolis: University of Minnessota Press, 1982.

SCHNEIDER, Anne; INGRAM, Helen. Social construction of target populations: implications for politics and policy. American Political Science Review, Cambridge, v. 87, n. 2, p. 334-347, June 1993.
}

30 
Quanto aos principais modelos de análise, Andrews (2013 ${ }^{31}$ ) faz a distinção entre a tradição econômica, mais próxima do que se refere ao modelo racionalista, e a tradição sócio-política, que tem relação com o modelo argumentativo/deliberativo. (2016, p. 14)

Secchi elabora um quadro que resume bem os pontos de convergência e de diferenças entre as duas abordagens de análise de políticas públicas:

QUADRO 2

PONTOS DE CONVERGÊNCIA E DE DIFERENÇAS ENTRE AS DUAS ABORDAGENS

\begin{tabular}{|c|c|c|c|}
\hline \multicolumn{2}{|c|}{ ANÁLISE } & RACIONALISTA & ARGUMENTATIVA \\
\hline \multirow[t]{3}{*}{$\begin{array}{l}\text { Elementos de } \\
\text { convergência }\end{array}$} & Origem & \multicolumn{2}{|c|}{$\begin{array}{l}\text { Lasswell, policy orientation: normatividade, foco na } \\
\text { resolução de problemas, multidisciplinaridade }\end{array}$} \\
\hline & Objetivo da análise & \multicolumn{2}{|c|}{$\begin{array}{l}\text { Prescrever: informar os atores políticos para ampará-los na } \\
\text { tomada de decisão sobre políticas públicas }\end{array}$} \\
\hline & Produto da análise & \multicolumn{2}{|c|}{ Relatório de Políticas Públicas } \\
\hline \multirow[t]{3}{*}{$\begin{array}{l}\text { Elementos } \\
\text { diferenciadores }\end{array}$} & Metodologia & Estruturada & $\begin{array}{l}\text { Não estruturada } \\
\text { (sensível ao contexto) }\end{array}$ \\
\hline & Epistemologia & Positivista & Interpretativista/construtivista \\
\hline & Papel do analista & $\begin{array}{l}\text { Analisar, sintetizar e fazer } \\
\text { recomendações políticas }\end{array}$ & $\begin{array}{l}\text { Mediar interesses, facilitar } \\
\text { participação, ajudar atores } \\
\text { políticos a formular e expressar } \\
\text { os seus argumentos }\end{array}$ \\
\hline
\end{tabular}

Fonte: Elaboração dos autores com base em Secchi (2016, p. 15).

Secchi, em Análise de políticas públicas (2016), apresenta, portanto, dois tipos de abordagens para análise de política pública, juntamente com os métodos, instrumentos, critérios e indicadores que cada uma delas emprega para a elaboração de um relatório prescritivo, desde o diagnóstico do problema até a formulação de recomendações para a solução do problema em pauta. Trata-se de uma obra que apresenta, de modo didático, como elaborar um relatório de análise ou de avaliação prescritiva, adotando a abordagem racionalista de matiz positivista, ou a abordagem argumentativa pós-positivista.

Apesar de a vertente argumentativa ou pós-positivista ter surgido em contraponto ao longo domínio da vertente racionalista de viés positivista no campo das Políticas Públicas, há uma tendência, a partir dos anos 2000, de convergência entre essas duas vertentes, no sentido de se afirmarem como metodologias complementares e não concorrentes. Essa é a posição defendida por Secchi (2016) ao afirmar que os dois tipos de análise não se excluem, mas traduzem perspectivas distintas em termos teóricos e práticos do que seja a política pública.

O próprio espectro dos valores empregados na análise racionalista tem sido ampliado no sentido da construção de critérios que abarcam "valores ou princípios presentes na sociedade", que operam como "mecanismos lógicos que servem como base para escolhas ou julgamentos” (SECCHI, 2013, p. 50). Os critérios mais 
adotados para confrontar resultados, conforme Weimer e Vining $\left(2011^{32}\right.$, apud SECCHI, 2016, p. 86), Bardach (200933, apud SECCHI, 2016, p. 86) e Secchi (2013), são viabilidade política, simplicidade, custo-benefício, produtividade, eficiência, eficácia/efetividade, legalidade, perenidade. Os critérios são operacionalizados por meio de indicadores que permitam mensurar o potencial de alguma alternativa de política pública.

Esse tipo de análise racionalista é muito empregado em avaliação ex ante, que, por meio de um relatório de recomendações fundamentadas em critérios e indicadores objetivos e mensuráveis, visa a fundamentar tecnicamente a tomada de decisão em termos da melhor alternativa de política pública a ser implementada para a resolução de um problema público. Esse modelo racionalista é mais adequado para resolução de temas técnicos estruturados, quando há pouca necessidade de legitimar publicamente, pois a análise tecnocrática por especialistas na área seria suficiente para a legitimação da tomada de decisão da administração pública.

Já a abordagem argumentativa/participativa de matiz pós-positivista implica a consulta pública dos atores envolvidos no problema, sendo mais indicada para problemas pouco estruturados, isto é, complexos e ambíguos, quando há tempo para engajar atores na construção de uma recomendação consensual (SECCHI, 2016, p. 63). A principal fonte para fundamentar a recomendação em um relatório argumentativo é o mapa da posição dos diferentes atores envolvidos na consulta pública, que pode ser um fórum de política pública (audiência pública, reunião pública). O analista ou organiza tal fórum, ou usa como fonte os dados que documentam tais reuniões. $\mathrm{O}$ analista também pode coletar dados em pesquisa de campo por meio de questionários, entrevistas, formulários, para analisar as percepções e demandas dos atores envolvidos na política pública em pauta. A análise dos dados coletados segue os métodos qualitativos e quantitativos amplamente usados nas pesquisas das Ciências Sociais.

Essa classificação das vertentes de análise de política pública entre positivistas e pós-positivistas é amplamente adotada na literatura internacional, conforme sistematizam Howlett, Ramesh e Perl em Política pública: seus ciclos e subsistemas (2013). Segundo os autores, os positivistas "acreditam que se pode realizar uma análise razoavelmente objetiva das metas ou objetivos e das consequências de uma política com o uso das metodologias-padrão da Ciência Social criadas para coletar dados e analisá-los" (BOBROW; DRYZEK, 1987; RADIN, 200034, LYNN, 1999³, apud HOWLETT; RAMESH; PERL, 2013, p. 10). Já os pós-positivistas adotam técnicas interpretativas ou mais subjetivas para ajudá-los a discernir e criticar os alvos, propósitos e ações do 
governo (TORGERSOM, 198636; THOMPSON, 200137; YANOW, 1999/2007³; DRYZEK, $2005^{39}$, apud HOWLETT; RAMESH; PERL, 2013, p. 10).

A principal distinção apontada por Howlett, Ramesh e Perl (2013) de métodos e abordagens reside justamente na diferença entre as duas atividades constitutivas da ciência da Política Pública, desde o texto seminal de Lasswell (1951): a análise de política pública (policy analysis) e o estudo de política pública (policy studies).

\begin{abstract}
A análise política tende a se concentrar na avaliação formal ou na apuração dos efeitos ou "impactos políticos" (policy impacts), por meio do uso frequente de técnicas quantitativas como a análise de custo-benefício (ACB) ou a avaliação e a gestão de risco (WEIMER \& VINING, $1992^{40}$ ). Ela envolve a determinação dos efeitos diretos e indiretos de políticas específicas, mediante o uso de técnicas estatísticas que visam analisar as conexões entre, por exemplo, programas governamentais específicos e várias consequências políticas (policy outcomes), como os indicadores de mudança e progresso social. (HOWLETT; RAMESH; PERL, 2013, p. 10)
\end{abstract}

Já os estudos de política pública (policy studies) “são mais amplos em escopo, examinando não apenas programas individuais e seus efeitos, mas também suas causas e pressuposições e os processos que levam à sua adoção” (2013, p. 11). Dentre os policy studies destacam-se os que visam a estabelecer algum tipo de nexo entre "alguns tipos particulares de políticas e a natureza dos regimes políticos (WOLFE, 198941; PRZEWORSKI; LIMONGI, 1997²)” (HOWLETT; RAMESH; PERL, 2013, p. 11).

Os autores destacam que, no campo da policy analysis, a abordagem positivista tem sido a dominante, sobretudo as vertentes que aplicam

[...] princípios da ciência econômica, em especial da economia do bem-estar, ${ }^{43}$ aos problemas públicos. Na verdade, muito daquilo que se identifica como pesquisa de policy

36 TORGERSON, Douglas. Between knowledge and politics: three faces of policy analysis. Policy Sciences, v. 19, n. 1, p. 33-59, 1986.

37 THOMPSON, W. B. Policy making through think and thin thick description as a methodology for communications and democracy. Policy Sciences, v. 34, p. 63-77, 2001.

38 YANOW, Dvora. Conducting interpretive policy analysis: on methods and practice. Critical policy Analysis, v. 1, n. 1, p. 110-122, 2007. 1ª edição de 1999

39 DRYZEK, John. Handle with care: the deadly hermeneutics of deliberative instrumentalism. Acta Politica, v. 40, p. 197-211, 2005 .

40 WEIMER, David L.; VINING, Aidan R. Policy analysis: concepts and practive. 2. ed. Englewood Cliffs, NJ: Prentice Hall, 1992

41 WOLFE, Joel D. Democracy and ecomomic adjustment: a comparative analysis of political change. In: FOGLESONG, R. E.; WOLFE, J.D. (org.). The politics of ecomomic adjustment. Nova York: Greenwood, 1989.

42 PRZEWORSKI, Adam; LIMONGI, Fernando. Modernization: theories and facts. World Politics, v. 49, p. 155-183, 1997.

43 "Os princípios da economia do bem-estar foram desenvolvidos inicialmente pelo economista britânico Alfred Pigou (1932), durante a I Guerra Mundial. Embora ele tenha identificado apenas alguns casos específicos de falhas de Mercado relacionadas à tendência de algumas indústrias em gerar monopólios e à incapacidade tanto dos consumidores como dos investidores de sempre dispor das informações necessárias à tomada de decisão econômica racional ou ótima, analistas posteriores argumentam em favor da existência de muito mais caos de falhas de Mercado (BATOR, 1958; ZERBE e MCCURDY, 1999)" (HOWLETT; RAMESH; PERL, 2013, p. 26). 
Essa vertente da economia do bem-estar social parte do pressuposto "de que se deve esperar que os indivíduos tomem a maioria das decisões sociais por meio de mecanismos de mercado" (2013, p. 26). É preciso observar que a vertente teórica dominante da economia do bem-estar nos Estados Unidos é aquela que adota o racionalismo econômico de matiz positivista como paradigma, portanto considera "que o mercado é o mecanismo mais eficiente para alocar os recursos da sociedade, mas admitem que eles não funcionam de modo adequado em todas as circunstâncias” (2013, p. 26).

Howlett, Ramesh e Perl situam no início da década de 1990 a "virada argumentativa” nos estudos de política pública, com o aparecimento dos pós-positivistas, “depois de uma insatisfação generalizada com a orientação tecnocrática que a disciplina havia tomado nas décadas anteriores com base nas máximas ortodoxas da economia do bem-estar "positivista'” (2013, p. 31). Os pós-positivistas criticam que as policy analysis convencionais com base na economia do bem-estar estão limitadas "em sua obsessão com a análise quantitativa, a separação objetiva entre fatos e valores e as conclusões generalizáveis e independentes de contextos sociais particulares, que são todas as marcas do pensamento 'positivista”” (2013, p. 31-32, itálicos nossos). Os autores ainda destacam que os pós-positivistas:

[...] enfatizam que a reflexão subjetiva, a análise normativa e a argumentação são ferramentas mais úteis para a compreensão das políticas públicas e da policy-making. Embora os pós-positivistas sejam influenciados por filosofias e métodos sociais mais gerais, como a teoria crítica, o pós-estruturalismo, o pós-modernismo e o construtivismo social, os quais tendem a negar a existência de um domínio objetivo de fatos independentes do observador, eles não se opõem à objetividade e à análise empírica em si. Pelo contrário, acreditam que a análise empírica (positivista) precisa ser combinada com a análise normativa (pós-positivista), porque as duas são inseparáveis, uma posição que foi de fato defendida por fundadores da policy sciences, como Harold Lasswell (conforme anteriormente citado). (2013, p. 32, itálicos nossos)

Howlett, Ramesh e Perl (2013) ainda enfatizam que os pós-positivistas criticam "a ênfase quase exclusiva na evidência empírica, presente nas análises positivistas", argumentam que as análises instrumentais de meios e fins, inspiradas na economia do bem-estar, são limitadas para compreender a complexidade de fatores que determinam as tomadas de decisão no campo das políticas públicas, pois "as políticas raramente têm objetivos livres de ambiguidade e raras vezes os policy-makers escolhem de fato os meios mais eficientes para alcançá-los”. Em contraponto, defendem que os fins e os meios de uma política pública "resultam de conflito e negociação constantes entre policy-makers orientados por seus valores 
e interesses”. Nesse viés, os pós-positivistas não consideram apenas limitada a abordagem positivista, mas "também lhe fazem objeção em termos éticos, ao argumentarem que ela promove uma gestão política burocrática 'de cima para baixo' e sufoca a democracia e a participação (HEINEMAN et al., 19904)” (HOWLETT; RAMESH; PERL, 2013, p. 32).

A análise pós-positivista não possui uma fórmula estabelecida, tal como o modelo da falha de mercado da economia do bem-estar adotada pela abordagem positivista, pois essa vertente não se configura como uma teoria formal, devendo antes ser compreendida como uma “orientação” teórica que compartilha pontos comuns. Howlett, Ramesh e Perl destacam alguns desses pontos na ampla revisão que fazem da literatura dessa vertente:

(I) “Os pós-positivistas não alimentam a pretensão de objetividade analítica e neutralidade política, mas assumem o papel de 'profissionais deliberativos que operam dentro de um claro arcabouço de valor que promove maior equidade social e política' (BURTON, 2006, p. 1745)" (apud HOWLETT; RAMESH; PERL, 2013, p. 33).

(II) “A necessidade de promover a democracia e a participação pública também ocupa lugar central no pensamento pós-positivista (DRYZEK, 2002 $\left.{ }^{46}\right)$. [...] Para tratar das lacunas, os pós-positivistas dão importância central a promover o 'acesso e explicação dos dados a todas as partes, a empoderar o público para que compreenda as análises e a promover discurso público sério’ (FISCHER, 2003, p. 15)” (apud HOWLETT; RAMESH; PERL, 2013, p. 33).

(III) “Portanto, os argumentos são a unidade básica de análise no pós-positivismo e o discurso, ou análise discursiva, é sua metodologia principal. Como explica Majone (1989, p. $7^{47}$ ), 'a tarefa do policy analyst consiste, sobretudo, em produzir evidências e argumentos a serem usados no curso do debate público'" (apud HOWLETT; RAMESH; PERL, 2013, p. 33).

(IV) “A argumentação jurídica, em que diferentes protagonistas preparam argumentos a favor e contra posições políticas particulares, serve de exemplo para mostrar a que se parece a análise pós-positivista e a formulação de políticas. As análises de oposição tomam a forma de um debate em que os participantes não só apresentam argumentos, mas também revelam suas normas, valores e circunstâncias” (HOWLETT; RAMESH; PERL, 2013, p. 33). 


\section{CONSIDERAÇÕES FINAIS}

Do exposto, pode-se inferir que tanto a análise de Secchi (2016) quanto a análise de Howlett, Ramesh e Perl (2013) adotam o debate entre as principais posições da epistemologia das ciências - a positivista e a pós-positivista - como pano de fundo para examinar as duas principais abordagens constitutivas do campo da Política Pública: a positivista/racionalista e a pós-positivista ou argumentativa/ construtivista. Uma chave importante para a compreensão da polêmica entre as distintas posições epistemológicas reside na distinção filosófica entre fato e valor, que foi reduzida a uma dicotomia pelos positivistas lógicos nos seguintes termos: "enunciados de fato" são "objetivamente verdadeiros”, enquanto “juízos de valor" "são incapazes de verdade objetiva e de garantia objetiva”, posição recusada por Putnam (2008).

Nesse viés, a análise crítica de Putnam (2008) sobre a epistemologia das ciências é uma chave importante para compreender a diferença entre valores cognitivos e valores normativos e, ao mesmo tempo, pôr em relevo a imbricação entre as atividades de descrição e avaliação em toda atividade científica, posto que toda pesquisa implica a escolha dos valores epistêmicos (metodologia e teoria de base) para descrever e explicar fatos, assim como a avaliação com base em valores e deliberação ética e política para a aplicação dos resultados.

Este artigo visou a fazer uma breve revisão do debate epistemológico entre positivistas e não positivistas de modo a tornar mais inteligível os pressupostos das duas principais posições epistemológicas que marcam o campo das policy analysis e dos policy studies. Vimos que a análise de políticas públicas em termos de avalição aplicada (policy analysis) foi dominada e difundida até a década de 1980 pela vertente positivista, que adotava como paradigma o modelo do racionalismo econômico vigente na economia do bem-estar.

Somente a partir da década de 1990 ocorreu a chamada virada argumentativa com o surgimento das abordagens pós-positivistas, que recusam a redução dos critérios de validade da objetividade dos métodos de análise a critérios e indicadores puramente quantitativo de viés matemático, estatístico, probabilístico e empírico centrados nos valores da eficácia, da eficiência e da efetividade econômica, pois acrescentam outros valores éticos, políticos e sociais à própria economia do bem-estar, tais como equidade, justiça e igualdade social, solidariedade, inclusão, etc.

Os pós-positivistas ampliam o campo dos estudos e das análises em políticas públicas quando substituem o monismo pelo pluralismo metodológico, na medida em que adotam, além dos valores cognitivos/epistêmicos e dos valores da racionalidade econômica, outros valores normativos (éticos, políticos, sociais, etc.) para a fundamentação das pesquisas, entrando em cena os chamados indicadores sociais e ambientais para analisar a eficácia e a eficiência do desenvolvimento em termos de sustentabilidade e de desenvolvimento social, em contraponto ao modelo de desenvolvimento apenas econômico.

Contudo, ao longo do século XX e do século XXI, essas posições epistemológicas, que, até os anos 1980, eram muito marcadas e fechadas, foram cada vez mais sendo imbricadas na própria práxis da policy analysis ou da análise de polí- 
ticas públicas, tendo em vista que o campo das Políticas Públicas e das Ciências Sociais, em geral, passa a adotar o pluralismo metodológico como uma das principais perspectivas epistemológicas e metodológicas. Nesse viés, as análises descritivas, as prescritivas, as análises teóricas e aplicadas, os modelos racionalistas, os métodos quantitativos, os modelos argumentativos e os métodos qualitativos passam a ser empregados inclusive em uma mesma pesquisa, como etapas e estratégias de pesquisas que adotam métodos mistos (qualitativos e quantitativos).

Nesse sentido, este artigo visou a contribuir para o debate contemporâneo sobre a epistemologia constitutiva do campo da ciência da Política Pública, demonstrando que as vertentes interpretativas mais relevantes, a positivista (racionalista) e a pós-positivista (construtivista, interpretativista, argumentativista, pós-estruturalista etc.), são fundamentadas teórica e metodologicamente na epistemologia das ciências, e que a compreensão desses pressupostos ajudam a escolher com mais clareza e rigor os métodos de análise e as abordagens metodológicas. A compreensão desse debate epistemológico também permite verificar a ampliação do campo da metodologia das ciências no sentido do pluralismo metodológico, evitando posições muito fechadas e dogmáticas, tendo em vista que hoje tanto os métodos quantitativos quanto os qualitativos são fundamentais e muitas vezes complementares para se chegar aos melhores resultados de uma pesquisa.

\section{REFERÊNCIAS}

ARRETCHE, Marta. Tendências no estudo sobre avaliação. In: RICO, Elizabeth Melo (org.). Avaliação de políticas sociais: uma questão em debate. São Paulo: Cortez, 1998. p. 29-39.

DESCARTES, Renée. Os Pensadores. São Paulo: Abril Cultural, 1973.

EASTON, David. A systems analysis of political life. Nova York: John Wiley, 1965.

FARAH, Marta. Análise de políticas públicas no Brasil: de uma prática não nomeada à institucionalização do “campo de públicas”. Revista de Administração Pública, Rio de Janeiro, v. 50, n. 6, p. 959-979, nov./dez. 2016.

HOWLETT, Michael; RAMESH, Mishra; PERL, Anthony. Política pública: seus ciclos e subsistemas.

Rio de Janeiro: Elsevier, 2013.

HUME, David. Tratado da natureza humana. São Paulo: Unesp, 2009.

KANT, Immanuel. Crítica da razão pura. Lisboa: Fundação Calouste Gulbenkian, 2001.

LASSWELL, Harold D. The policy orientation. In: LERNER, Daniel; LASSWELL, Harold D. The policy sciences: recent developments in scope and method. Stanford, CA: Stanford University Press, 1951. p. 3-15.

LERNER, Daniel; LASSWELL, Harold D. The policy sciences: recent developments in scope and method. Stanford: Stanford University Press, 1951.

LINDBLOM, Charles. Muddling through 1: a ciência da decisão incremental. In: HEIDEMANN, Francisco; SALM, José Francisco (org.). Políticas públicas e desenvolvimento: bases epistemológicas e modelos de análise. Brasília: Editora UnB, 2014a. p. 161-180. 1ª edição publicada em 1979.

LINDBLOM, Charles. Muddling through 2: a ubiquidade da decisão incremental. In: HEIDEMANN, Francisco; SALM, José Francisco (org.). Políticas públicas e desenvolvimento: bases epistemológicas e modelos de análise. Brasília: Editora UnB, 2014b. p. 181-202. 1ª edição publicada em 1979. 
MARICONDA, Pablo Rubén. O controle da natureza e as origens da dicotomia entre fato e valor. Scientiae Studia, São Paulo, v. 4, n. 3, p. 453-472, 2006.

PUTNAM, Hilary. O colapso da verdade e outros ensaios. Aparecida, SP: Ideias e Letras, 2008.

QUINE, Willard Van Orman. From a logical point of view. Cambridge: Harvard University Press, 1953.

SECCHI, Leonardo. Análises de políticas públicas: diagnóstico de problemas e recomendação de solução. São Paulo: Cengage Learning, 2016.

SECCHI, Leonardo. Políticas públicas: conceitos, esquemas de análise, casos práticos. São Paulo: Cengage Learning, 2013.

SIMON, Herbert A. Modelo comportamental de escolha racional. In: HEIDEMANN, Francisco; SALM, José Francisco (org.). Políticas públicas e desenvolvimento: bases epistemológicas e modelos de análise. 3. ed. Brasília: Editora UnB, 2014. p. 143-164. 1ª edição publicada em 1955.

WITTGENSTEIN, Ludwig. Tratado lógico-filosófico. Lisboa: Fundação Calouste Gulbekian, 1987.

NOTA: Este artigo foi escrito em regime de contribuição total do primeiro autor e contribuição parcial do segundo autor em colaboração.

\section{COMO CITAR ESTE ARTIGO}

RAMACCIOTTI, Bárbara Lucchesi; BERNARDINO, Marjorie Cristina da Cruz. Vertentes epistemológicas das políticas públicas: entre as análises descritiva e prescritiva. Cadernos de Pesquisa, São Paulo, v. 50, n. 175, p. 56-76, jan./mar. 2020. https://doi.org/10.1590/198053146645 
